\title{
Morphological variation in the female reproductive tract of Australian rodents in the genera Pseudomys and Notomys
}

\author{
W. G. Breed
}

Department of Anatomy \& Histology, The University of Adelaide, Adelaide, South Australia 5001, Australia

\begin{abstract}
Summary. Morphological studies of the vagina and cervix from females of several species of Pseudomys (pseudo-mice) and Notomys (hopping-mice) have shown marked interspecific differences. In females of all four species of Pseudomys and in $N$. cervinus there was a relatively thin walled, dorsoventrally flattened, vagina with a large lumen, longitudinal epithelial folds, and conspicuous fornices. By contrast, in females of $N$. alexis and $N$. mitchelli the vagina had a much smaller lumen, few or no folds, minute fornices, but a well developed muscle coat. The cervix of the Pseudomys females was a conspicuous fibrous structure, rich in collagen, with two canals throughout its length. In $N$. cervinus females it was smaller and the two canals, although separated by a median septum for much of their lengths, joined just before the external os. In $N$. alexis and $N$. mitchelli females the cervix was much less extensive, its boundaries could not be discerned externally, and, histologically, it was more cellular and less fibrous. This variation in morphology of the female reproductive tract appears to complement that of the excurrent ducts, accessory sex glands and external genitalia of males of these species of Australian murid rodents.
\end{abstract}

\section{Introduction}

In the two murid rodent genera, Pseudomys (pseudo-mice) and Notomys (hopping-mice), considerable interspecific variation of male reproductive tract anatomy has been found. Individuals of some species of Pseudomys have large testes and high numbers of spermatozoa in the epididymis, in males from other species the testes are much smaller and lower numbers of spermatozoa occur, whereas minute testes and even fewer epididymal spermatozoa are present in males of 3 species of Notomys (Breed, 1982). Such differences in testicular size and numbers of spermatozoa presumably reflect interspecific variation in sperm numbers normally deposited at ejaculation. The arrangement of accessory glands also varies between the species, with males of all species of Pseudomys and of $N$. cervinus having large seminal vesicles and coagulating glands but, in males of 3 other species of Notomys, these glands are extremely small (Breed, 1981a, b, 1982), and no vaginal plug is evident externally in recently mated females. In addition, a divergent glans penis with a narrow shaft and very large, dorsally pointing, spines occurs in $N$. alexis and $N$. mitchelli males (Morrissey \& Breed, 1982).

Since the cervix is considered to be a partial barrier to sperm transport in some mammals (Bedford, 1972; Thibault, 1973; Overstreet \& Katz, 1977; Matthews \& Adler, 1979), and a vaginal plug is necessary for this to occur in the laboratory rat (Blandau, 1945, 1973; Matthews \& Adler, 1977,1978 ), it was thought possible that the interspecific variation in the reproductive tract of a 
male Pseudomys and Notomys might be associated with anatomical variation in the lower region of the female tract. The following study was therefore carried out to investigate this possibility.

\section{Materials and Methods}

Females of the species Pseudomys australis $(\mathrm{N}=4), P$. nanus $(\mathrm{N}=4)$, and Notomys alexis $(\mathrm{N}=12)$ were injected intraperitoneally with 5 or $10 \mathrm{i} . \mathrm{u}$. PMSG and, $48 \mathrm{~h}$ later, with the same dose of hCG at which time the animals were placed with known fertile males. The following morning the females were killed and the reproductive tracts removed. Tracts were also obtained at various stages of the oestrous cycle from females of 10 other $P$. australis (mean body weight $65 \mathrm{~g}$ ), 20 N. alexis (mean body weight $35 \mathrm{~g}$ ), 10 P. nanus (mean body weight $34 \mathrm{~g}$ ), 5 P. hermannsburgensis (mean body weight $12 \mathrm{~g}$ ), $4 P$. apodemoides (mean body weight $20 \mathrm{~g}$ ), $6 \mathrm{~N}$. cervinus (mean body weight $35 \mathrm{~g}$ ), and $5 \mathrm{~N}$. mitchelli (mean body weight $50 \mathrm{~g}$ ) (see Watts \& Aslin, 1981; Strahan, 1983, for general description of these species).

For gross morphology some tracts were cut along the ventral surface so that the vaginal wall could be pinned out and its size, as well as that of the cervix, could be determined. Other tracts were pinned out intact, fixed in $10 \%$ neutral buffered formalin, and subsequently cut in a frontal plane.

For histological examination, some of the vaginal tissue was fixed in $0.1 \mathrm{M}$-phosphate-buffered glutaraldehyde/formaldehyde, subsequently rinsed in the buffer, dehydrated and embedded in Spurrs resin. Sections, $0.5-1 \mu \mathrm{m}$ in thickness, were cut on an ultramicrotome and stained with toluidine blue in borate buffer. For other investigations, tissue was fixed in buffered formalin or Bouin's fluid and transverse or longitudinal sections of paraffin wax-embedded material were cut on a rotary microtome. The sections were stained with haematoxylin and eosin, Masson's trichrome and van Gieson's stain for collagen, periodic acid-Schiff (together with diastase controls) for mucopolysaccharides, or Gomori's method with aldehyde fuchsin for elastic fibres (see Drury \& Wallington, 1967).

\section{Results}

\section{Macroscopic anatomy}

The morphology of the reproductive tract was similar in females of all 4 species of Pseudomys investigated and a large vaginal plug occurred in the mated animals. The vagina was relatively thin walled, dorso-ventrally flattened and, at dissection, had a large lumen and longitudinal folds throughout its length. At the cranial end there was a large fornix (Text-fig. 1). The cervix was bulky, protruded deeply into the vagina, and two laterally flattened canals occurred. A median septum was therefore present throughout the cervix and it protruded as a wedge-shaped structure into the vagina (Text-fig. 1). Externally, the cervix appeared hard, white, and fibrous.

In the females of Notomys the tract morphology was very different and interspecific variation was evident. In $N$. cervinus females the vagina was again thin walled, dorso-ventrally flattened, with longitudinal folds. Cranially a dorso-medial ridge occurred (Text-fig. 1), and the fornices were conspicuous, although not as deep as those in females from most of the Pseudomys species. The cervix, although evident externally, was less massive than in females of Pseudomys. A medial septum was evident for much of its length (Text-fig. 1), but the two canals were joined distally just before reaching the external os. The gross anatomy of the tracts of $N$. alexis and $N$. mitchelli females was markedly different from that in the $N$. cervinus individuals, but it was similar in animals from both species. At initial dissection, the position of the cervix could not be determined. The vagina was invariably very small, lacked longitudinal folds for much of its length and was oval in shape. Internally a minute dorso-ventrally flattened lumen was evident, and there was a well developed muscle layer. The vagina merged into the cervix the wall of which was not much thicker than that 

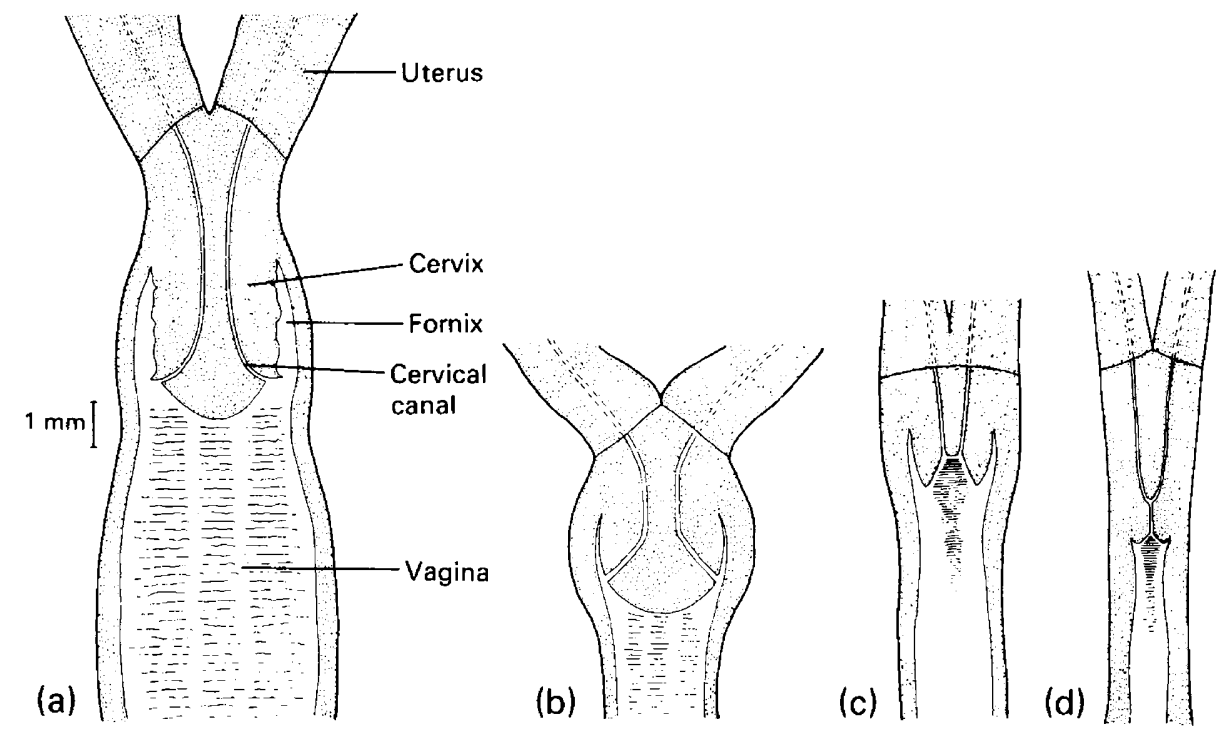

Text-fig. 1. Camera lucida drawings of lower region of female reproductive tracts of (a) Pseudomys nanus; (b) P. hermannsburgensis; (c) Notomys cervinus; and (d) N. alexis. Note the large differences in width of the vaginal lumen, size and structure of the cervix and its canals. All drawings to the same scale.

of the vagina. The fornices were extremely shallow, inconspicuous, and sometimes impossible to discern at gross dissection. There appeared to be a single external os, and a very small canal distally which became divided cranially by a median septum (Text-fig. 1).

\section{Microscopic anatomy}

The vagina from all Pseudomys females had a highly convoluted lining of stratified squamous epithelium (PI. 1, Fig. 1). Transverse sections of the cranial region indicated that the fornix was a crescent-shaped structure with the cervix attached dorsally to the vaginal wall (Pl. 1, Fig. 2). The lateral parts of the fornix were more extensive and extended further cranially (PI. 1, Fig. 3). Trichrome stain showed that the lamina propria of the vagina had abundant collagen fibres and staining with aldehyde fuchsin indicated a scattering of elastic fibres which sometimes appeared especially abundant just beneath the epithelial layer. The outer muscle coat was extremely thin and there were scattered collagen and elastic fibres present amongst the muscle cells.

The histology of the vagina of $N$. cervinus females was like that in the females of Pseudomys, but in $N$. alexis and $N$. mitchelli individuals the lumen was much smaller, generally elliptical in crosssection, and the epithelium usually lacked the longitudinal folds (PI. 1, Fig. 4). In the lamina propria fibroblasts tended to be more abundant than in the vagina from the above species ( $\mathrm{Pl} .1$, Fig. 5). There were many collagen and elastic fibres; the latter generally being most numerous just beneath the epithelial layer. The muscle coat, the fibres of which ran mainly longitudinally, was considerably more extensive than in female Pseudomys (usually being 50-200 $\mu \mathrm{m}$ in cross-section). In serial sections of recently mated animals a small plug was found at the cranial end of the vagina (Pl. 1, Fig. 6), which had not been evident at external examination.

In the cervix of the Pseudomys females two laterally flattened canals (Pl. 1, Figs $2 \& 3$ ) were present and had stratified squamous epithelium for much of their lengths. The lamina propria was more cellular than that in the vagina but abundant collagen and scattered elastic fibres occurred throughout. The muscle coat was thick and its fibres ran in various directions. In $N$. cervinus 
females a single cervical canal was present in the region of the fornix (Pl. 1, Fig. 7), but two laterally flattened canals were present for much of the cervix (Pl. 2, Figs 8 \& 9). In N. alexis and N. mitchelli individuals the fornix was much smaller (Pl. 2, Fig. 10), a single cervical canal was present distally, but stratified squamous epithelium continued beyond its point of bifurcation (Pl. 2, Fig 11 \& 12) and, at the cranial end of the cervix, there was a region where columnar epithelial cells overlay several layers of stratified squamous cells (P1. 2, Fig. 13). The lamina propria of the cervix was often more cellular than that of the vagina. Nuclei varied considerably in shape, but most were elongated and vesicular. Some appeared similar to those of the uterine stroma, whereas others were more like nuclei of smooth muscle cells or, occasionally, fibroblasts. In addition, between the cells, many collagen and scattered elastic fibres were evident. Compared to Pseudomys and $N$. cervinus females, however, the cervix of $N$. alexis and $N$. mitchelli individuals generally had a greater density of cells and less collagen. Above the cervix the uterine tissue had less densely packed, more regularly arranged, stromal cells between which fewer collagen and virtually no elastic fibres occurred. The muscle layers of the cervix were extensive but their boundaries, in contrast to those of the uterus, were not well defined. In the cervix the fibres ran in various directions, but sometimes an inner circular layer could be seen, and there was invariably an outer layer of longitudinal muscle that extended for the whole length of the tract.

\section{Discussion}

The genera Pseudomys and Notomys, together with Mastacomys (broad-toothed rats), form a monophyletic group within the hydromyine rodents of Australia (Baverstock, Watts, Gelder \& Janake, 1983). Nevertheless, the genus Pseudomys is fairly variable morphologically, whereas all species of Notomys are very similar in external appearance (Watts \& Aslin, 1981; Strahan, 1983) and genetic evidence indicates that the Notomys species form a tight cluster to the exclusion of all others (Baverstock, Watts, Adams \& Cole, 1981). However, this study, and the previous one on the

\section{PLATE 1}

All sections were of paraffin-wax embedded material and stained with haematoxylin and eosin, except those of Figs $4 \& 5$ which were embedded in plastic and stained with toluidine blue. VG $=$ vagina $; \mathbf{F X}=$ fornix $; \mathrm{EO}=$ external os $; \mathrm{CC}=$ cervical canal $; \mathrm{VP}=$ vaginal plug $; \mathrm{EL}=$ epithelial layer; $L P=$ lamina propria.

Fig. 1. Transverse section of part of vagina from a female $P$. australis showing a highly folded stratified squamous epithelial lining and a lamina propria in which abundant collagen fibres occur. $\times 90$.

Fig. 2. Transverse section of cervico-vaginal junction of a female $P$. australis showing that there are laterally flattened cervical canals that diverge a little ventrally. $\times 38$.

Fig. 3. Transverse section of cervix of a female $P$. australis slightly more cranial than that in Fig. 2 showing a large extension of the fornix lateral to the cervical canals. $\times 33$.

Fig. 4. Transverse section of vagina from a female $N$. alexis showing small, oval shaped, lumen, lack of longitudinal folds, and fairly thick muscle coat. $\times 32$.

Fig. 5. Transverse section of vagina from a female $N$. alexis showing cellular lamina propria. $\times 80$.

Fig. 6. Cranial transverse section of vagina of a recently mated female $N$. alexis showing vaginal plug in lumen. This had not been visible at external examination. $\times 53$.

Fig. 7. Transverse section of cervico-vaginal junction of a female $N$. cervinus showing fairly large fornix laterally. $\times 46$. 
PLATE 1
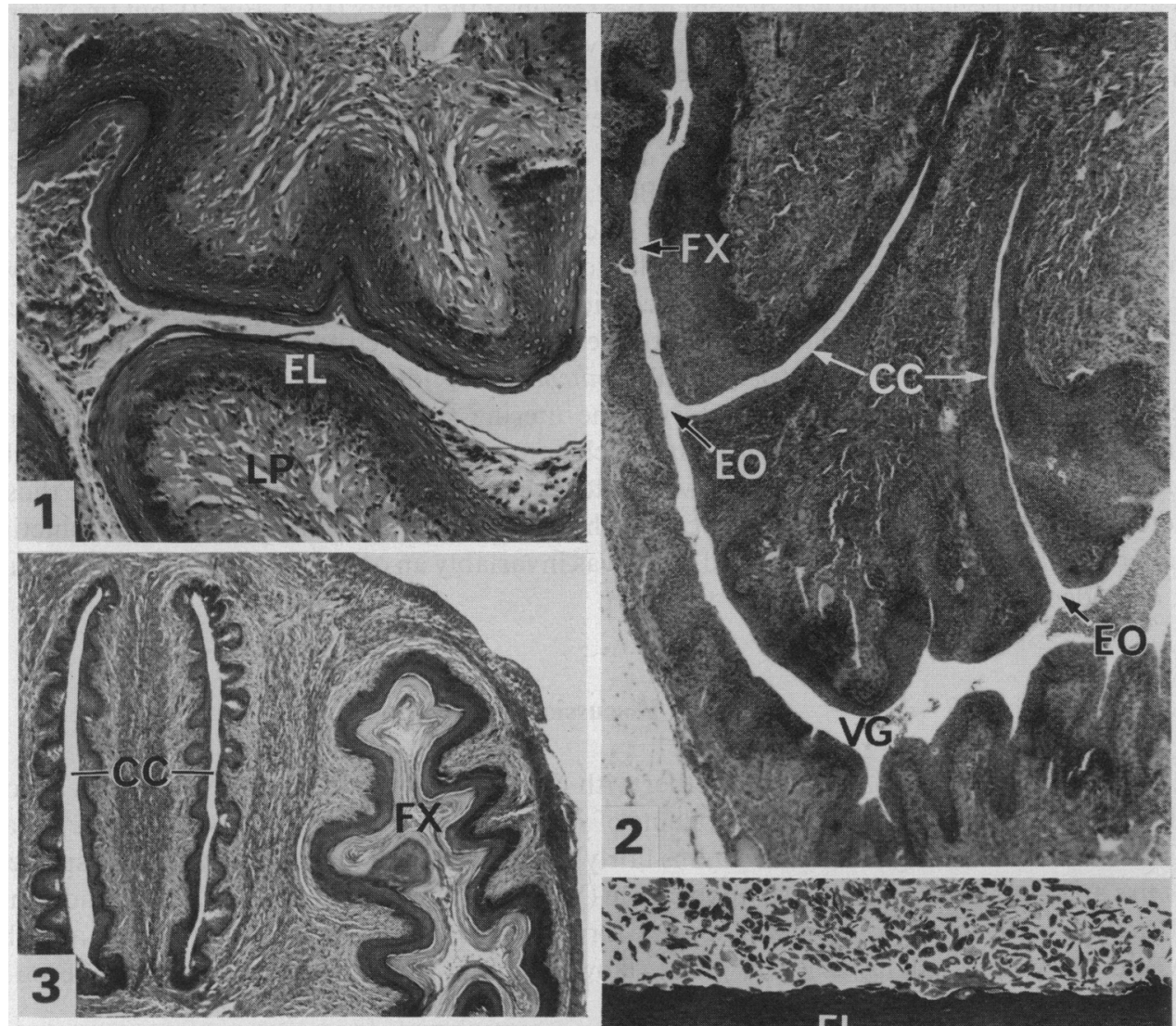

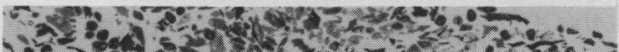

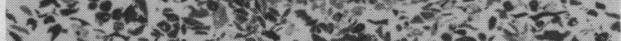

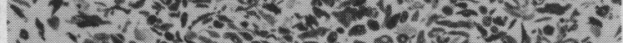

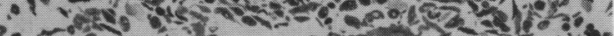

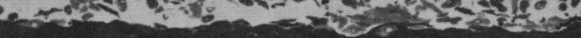

\section{EL}
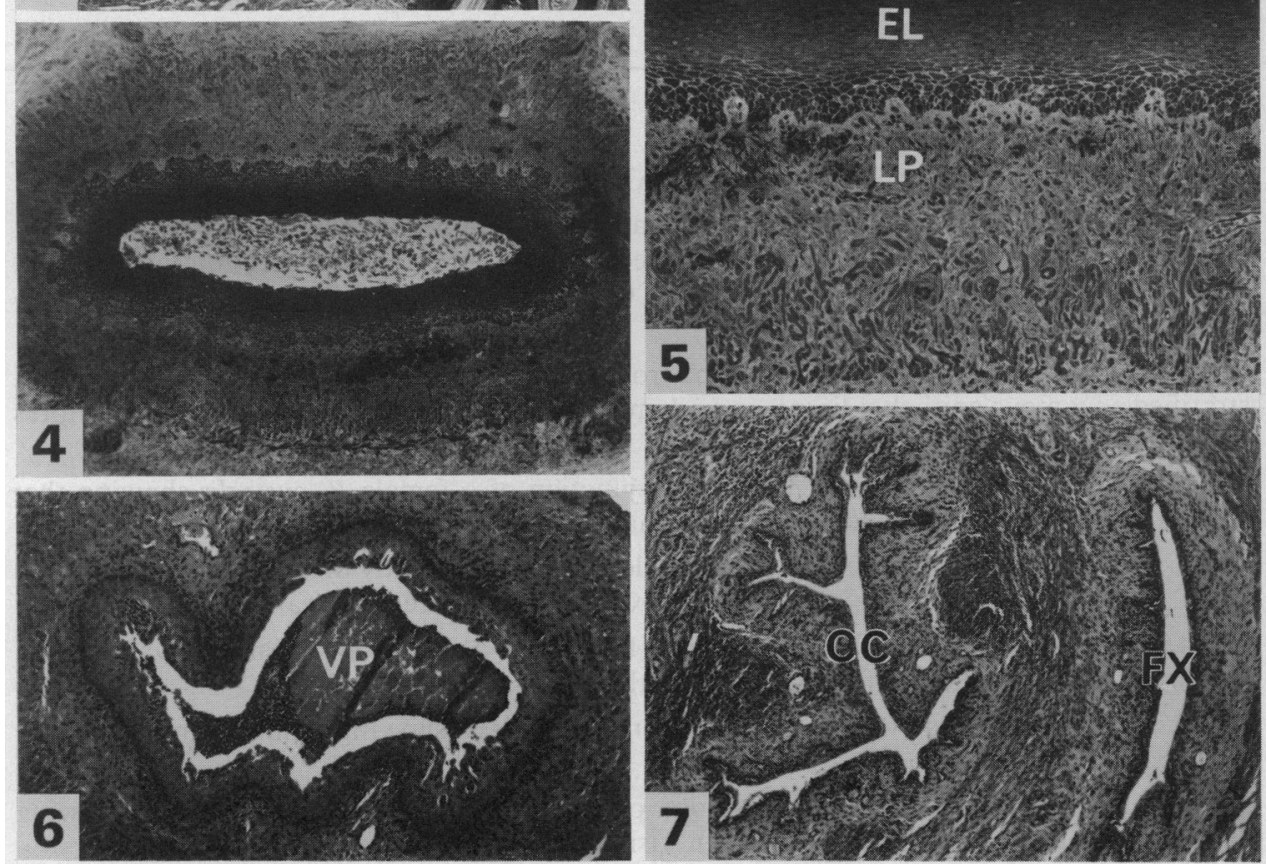

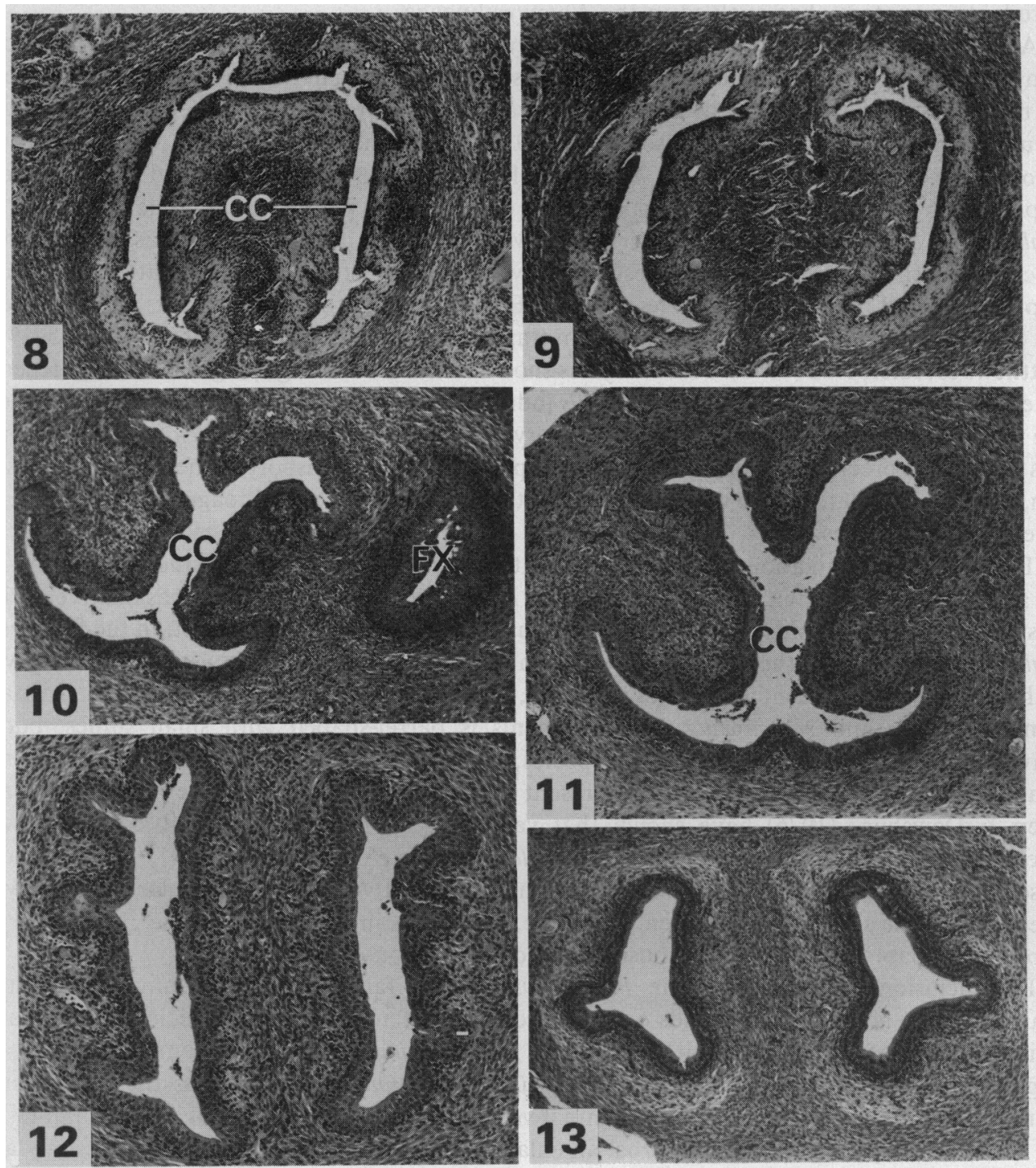

All sections are of paraffin-wax embedded material and stained with haematoxylin and eosin.

Fig. 8. Transverse section of distal part of cervix of a female $N$. cercinus showing two laterally flattened canals $(C C)$ joined dorsally. $\times 46$.

Fig. 9. Transverse section of more cranial part of cervix of a female $N$. cercinus showing two canals separated by a median septum. $\times 46$.

Figs 10-13. Transverse sections of cervix from a female $N$. alexis passing from distal (Fig. 10) to cranial (Fig. 13) region. All sections from the same individual. Note very small fornix, single medial canal (CC) distally which divides into two cranially, stratified squamous epithelium passing up to beyond the point of bifurcation, and more cellular lamina propria compared to that in cervix from female $N$. cervinus (Figs 7-9). Also note difference in shape of cervical canals to those of $N$. cerrinus (Figs 7.9), and P. australis (Figs $2 \& 3$ ) females.

Fig. 10, $\times 53$; Fig. 11, × 62; Fig.12, $\times 80 ;$ Fig. 13, $\times 53$. 
anatomy of the male reproductive tract (Breed, 1982), have shown that considerable divergence in reproductive anatomy has evolved in the Notomys lineage.

Although males from the species of Pseudomys studied in this investigation have previously been found to have marked differences in numbers of spermatozoa in the epididymis (Breed, 1982), the morphology of the cervix in the females was similar throughout the genus. In general it resembled that of the laboratory rat (see Hafez, 1973), except that it tended to be more bulky in the region of the external ora cervices. In $N$. cervinus females, however, the cervix did not protrude so deeply into the vagina and the two canals became confluent just before reaching the external os. In $N$. alexis and $N$. mitchelli females the cervix was very different; it did not appear as a hard fibrous structure externally, its wall was far less extensive, and, on histological examination, its lamina propria appeared more cellular and less fibrous. Experiments with laboratory rats have indicated that a large vaginal plug is essential for sperm transport through the cervix (Blandau, 1945, 1973; Matthews \& Adler, 1977, 1978). This study has shown that a similar large plug occurs in the recently mated Pseudomys females, but in the $N$. alexis individuals it is minute and is not visible externally. The much smaller, less fibrous, nature of the cervical wall in females of $N$. alexis and $N$. mitchelli thus appears to preclude the necessity of a large plug for sperm transport in these species; this, in turn, presumably relates to the vestigial nature of the seminal vesicles and coagulating glands in the males of these species.

The present investigation has also shown that there is a marked interspecific variation in the size and shape of the vagina. In all Pseudomys and $N$. cervinus females the lumen was relatively wide, conspicuous epithelial folds occurred, and the muscle wall was thin. By contrast, in the females of $N$. alexis and $N$. mitchelli the vagina and its lumen were much smaller in cross-section, generally no epithelial folds were present for most of its length, but there was an extensive muscle coat. In males from Pseudomys and $N$. cervinus the glans penis is barrel-shaped with small spines, but in individuals from the other extant Notomys species, the glans penis narrows considerably towards its tip and much larger spines on its shaft are present (Morrissey \& Breed, 1982). Dewsbury (1975) and Estep \& Dewsbury (1976) have shown that variation in phallic morphology correlates with differences in copulatory behaviour and in $N$. alexis 'locking' has been found (D. A. Dewsbury, personal communication). The evolution of the comparatively thick muscular vaginal wall, together with the small vaginal lumen, and large, dorsally pointing, spines on the glans penis are therefore probably related to this unusual type of copulation.

In conclusion, it appears that in Pseudomys males a fairly typical, presumably ancestral, arrangement of accessory sex glands occurs; tracts of the females of these species are also fairly similar to those of many other murids. In males of $N$. cervinus similar large seminal vesicles and coagulating glands are present, but in $N$. alexis and $N$. mitchelli individuals the reproductive anatomy is very different, with minute seminal vesicles and coagulating glands, very small testes, low numbers of epididymal spermatozoa, an enlarged distal end of the ductus deferens, and large spines on the glans penis (Breed, 1981a, b, 1982; Morrissey \& Breed, 1982). This study has shown that, in $N$. cervinus females, the distal region of the reproductive tract is not very different from that in the Pseudomys individuals, but in females of the two other Notomys species it is, like that of the males, greatly divergent. Within these hydromyine rodents, therefore, the differences in the reproductive anatomy of the male and female tracts appear to be complementary specializations. Fooden (1970) has previously found, in macaques, a relationship between the morphology of the glans penis, and that of the vagina and cervix, and he considered that the distinctive arrangement in Macaca arctoides animals may have evolved as a reproductive isolating mechanism. A similar argument could be used to explain some of the evolutionary divergence of the reproductive anatomy of male and female $N$. alexis and $N$. mitchelli. Probably more relevant to interpreting many of the present findings, however, are the studies on North American muroids for which there is some suggestive evidence that a relationship occurs between accessory sex gland modification, apparent absence of vaginal plugs, 'locking' during copulation, and breeding system. The various anatomical features of the reproductive tract of $N$. alexis, together with the occurrence of 'locking' 
during copulation, and very small testes, all suggest a monogamous mating system (Hartung \& Dewsbury, 1978; Voss, 1979; Dewsbury, 1981; Harcourt, Harvey, Larson \& Short, 1981). However, the laboratory and, albeit very sparse, field observations carried out so far do not support this suggestion (Happold, 1976; Breed, 1981b, 1982). Both $N$. alexis and $N$. mitchelli are usually restricted to the stabilized sandhills of the arid and semi-arid regions of Australia where the animals live in deep burrow systems (Watts \& Aslin, 1981; Strahan, 1983). So far no comprehensive field investigations have yet been performed, but a study of their socioecology and breeding system in the natural environment could, perhaps, shed some light on the significance of the highly divergent reproductive anatomy that occurs in these species of murid rodents.

I thank Chris Watts, Peter Baverstock, Mike Thompson and Clive Crouch for supplying some of the animals and Gail Hermanis, Chris Leigh and Rob Murphy for technical assistance.

\section{References}

Baverstock, P.R., Watts, C.H.S., Adams, M. \& Cole, S.R. (1981) Genetical relationships among Australian rodents (Muridae). Aust. J. Zool. 29, 283-303.

Baverstock, P.R., Watts, C.H.S., Gelder, M. \& Janake, A. (1983) G-banding homologies of some Australian rodents. Genetica $60,105-117$.

Bedford, J.M. (1972) Sperm transport, capacitation and fertilization. In Reproductive Biology, Ch.6, pp. 338 392. Eds H. Balin \& S. Glasser. Excerpta Medica, Amsterdam.

Blandau, R.J. (1945) On the factors involved in sperm transport through the cervix uteri of the albino rat. Am. J. Anat. 77, 253-272.

Blandau, R.J. (1973) Sperm transport through the mammalian cervix : comparative aspects. In Biology of the Cervix, Ch. 15, pp. 285-304. Eds R. J. Blandau \& K. Moghissi. University of Chicago Press, Chicago.

Breed, W.G. (1981 a) Histology of accessory sex organs and extra-gonadal sperm reserves in the male hopping mouse Notomys alexis. Archs Androl. 7, 357360.

Breed, W.G. (1981b) Unusual anatomy of the male reproductive tract in Notomys alexis (Muridae), $J$. Mammal. 62, 373-375.

Breed, W.G. (1982) Morphological variation in the testes and accessory sex organs of Australian rodents in the genera Pseudomys and Notomys. J. Reprod. Fert. 66, 607-613.

Dewsbury, D.A. (1975) Diversity and adaptation in rodent copulatory behaviour. Science, N.Y. 190, 947954.

Dewsbury, D.A. (1981) An exercise in the prediction of monogamy in the field from laboratory data on 42 species of muroid rodents. The Biologist 63, 138-162.

Drury, R.A.B. \& Wallington, E.A. (1967) Carleton's Histological Technique, 4th edn. Oxford University Press.

Estep, D.Q. \& Dewsbury, D.A. (1976) Copulatory behaviour of Neotoma lepida and Baiomys taylori: relationship between penile morphology and behaviour. J. Mammal. 57, 570-573.

Fooden, J. (1970) Complementary specialization of male and female reproductive structures in the bear macaque, Macaca arctoides. Nature, Lond. 214, 939 941 .
Hafez, E.S.E. (1973) The comparative anatomy of the mammalian cervix. In Biology of the Cervix, Ch. 3, pp. 23-56. Eds R. J. Blandau \& K. Moghissi. University of Chicago Press, Chicago.

Happold, M. (1976) Social behaviour of the conilurine rodents (Muridae) of Australia. Z. Tierpsychol. 40, 113-182.

Harcourt, A.H., Harvey, P.H., Larson, S.G. \& Short, R.V. (1981) Testis weight, body weight and breeding system in primates. Nature, Lond. 293, 55-57.

Hartung, T. G. \& Dewsbury, D.A. (1978) A comparative analysis of copulatory plugs in muroid rodents and their relationship to copulatory behavior. J. Mammal. 59, 717-723.

Matthews, M.K. \& Adler, N.T. (1977) Facilitative and inhibitory influences of reproductive behaviour on sperm transport in rats. J. comp. Physiol. Psychol. 91, $727-741$.

Matthews, M.K. \& Adler, N.T. (1978) Systematic interrelationship of mating, vaginal plug position, and sperm transport in the rat. Physiol. Behav. 20, 303309.

Matthews, M.K. \& Adler, N.T. (1979) Relative efficiency of sperm transport and number of sperm ejaculated in the female rat. Biol. Reprod. 20, 540-544.

Morrissey, B.L. \& Breed, W.G. (1982) Variation in external morphology of the glans penis of Australian native rodents. Aust. J. Zool. 30, 495-502.

Overstreet, J.W. \& Katz, D.F. (1977) Sperm transport and selection in the female genital tract. In Development in Mammals, Vol. 2, pp. 31-65. Ed. M. H. Johnson. North-Holland Publ. Co., Amsterdam.

Strahan, R. (1983) The Australian Museum Complete Book of Australian Mammals. Angus \& Robertson, Sydney.

Thibault, C. (1973) Sperm transport and storage in vertebrates. J. Reprod. Fert., Suppl. 18, 39-53.

Voss, R. (1979) Male accessory glands and the evolution of copulatory plugs in rodents. Occ. Pap. Mus. Zool. Univ. Mich. 689, 1-17.

Watts, C.H.S. \& Aslin, M. (1981) The Rodents of Australia. Angus \& Robertson, Sydney. 